\title{
A remote epileptic patient supervising system
}

\author{
Vasumathi D. Majety*, G. Murali \\ Department of Computer Science, Acharya Nagarjuna University, Guntur 522510, Andhra Pradesh, India
}

Corresponding Author Email: mvasudeviravinuthala@gmail.com

https://doi.org/10.18280/ama_b.610405

Received: 29 August 2018

Accepted: 23 November 2018

\section{Keywords:}

Zigbee transceiver, ardunio, heart rate, body temperature

\begin{abstract}
A Remote Epileptic Patient Monitoring (REPM) system is presented to sense epileptic seizure of a patient and to protect the patient' fall down. With the aid of telecommunication techniques, the system is capable enough to provide health care in remote places. Physiological sensors and Zigbee transceiver are the heart of the system to recognize patient's epileptic seizure. The epileptic seizure patients are supported by the system even in acute cases. The brilliant epilepsy recognition can be achieved by selected parameters of the patient. Generally according to neuro science epilepsy is of three categories (Motor, Sensory and Psychogenic seizures) Motor seizures can only get predicted as it is convulsive. Whereas Sensory and Psychogenic seizures cannot be observed even in seizure duration also. A sensory seizure is a type of simple partial seizure. The Sensory and Psychogenic seizures are assaults that may look like epileptic seizures, yet are not caused by unusual cerebrum electrical releases. They are an indication of mental misery. So I proposed a system to accurately recognize Motor seizures with the aid of wireless technology. Utilizing that pack we can anticipate the patient who may fall in danger. The REPM will be reasonable, distinguishes the variations and additionally alerts by a SMS to the respective individual for the patient's life saving purpose. To realize all the above strategy I have used Temperature sensor, Heart beat sensor, Blood pressure, MEMS and Zigbee module utilizing Arduino.
\end{abstract}

\section{INTRODUCTION}

Biomedical sensors benefit from the increase in growth of wireless technology for measuring different parameters which effects seizure. The utilization of wireless technology in medicinal services frameworks gives extraordinary portability and provides comfort level of patients [1-4]. A patient's body temperature, heart rate, blood pressure and MEMS data are send to receiver system wirelessly using zigbee .

The epilepsy is a neurological disorder. Due to small electric power generated in brain. A shock is observed which makes the patient unconscious and fall down. There is a strong requirement of long term and continuous monitoring of a patient even at remote places [5]. With the aid of wireless technology and electronic sensors I proposed a Remote Epileptic Patient Monitoring system (REPM). Arduino allows upto 5 different sensors and in my system I used only 4 combinations of sensors connected to the Arduino. The micro controller is programmed to sense and collect the data. The patient epileptic behavior is recognized with disturbance in heart beat, blood pressure and temperature of the patient' body. The REPM algorithm is designed in such a way that to combine all these interrelated parameters and alert the patient coordinator.

In this present scenario, patient'sepilepsy condition may not get be treated with in hospital environment by a doctor all the time. So I proposed this work to make valuable for everybody in this general public. Again a doctor far away from the patient need to know the patient situation and to detect seizure occurrence. The heart rate, body temperature, blood pressure and convulsions of the patient can be measured using an Embedded system. 2.BASICDESIGN

Epilepsy is a standout amongst the most widely recognized essential ailments of the sensory system. The epileptic patient can get be treated if he is in the hospital environment, but if he cannot get treatment in remote places. This paper describes the working of REPM system which consists of sensors and GPS module by which the patient can be treated where ever he is in (remote area). Epilepsy can be detected using different parameters. In this paper we proposed an algorithm to detect epilepsy which improves the accuracy and also address the false alarms. The algorithm uses four parameters of the patient. Those are patient body temparature, Blood pressure, Heart rate and convulsions.

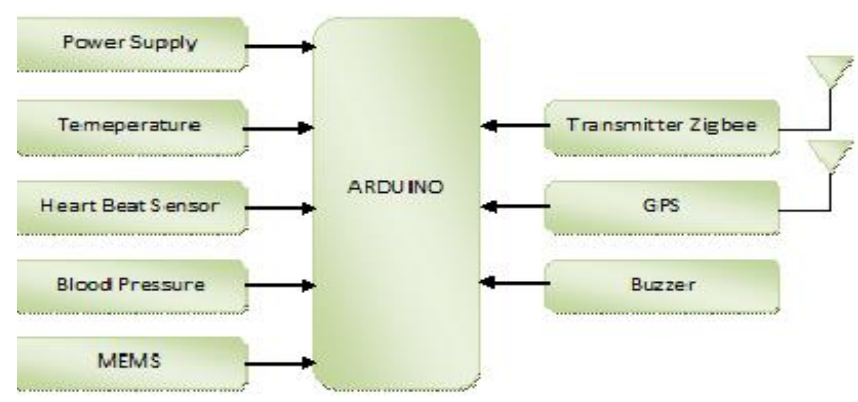

Figure 1. Block diagram of transmitter 


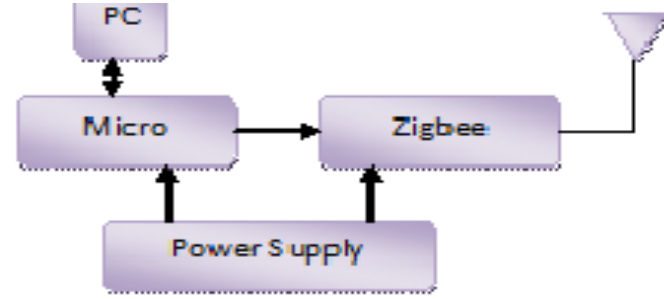

Figure 2. Block diagram of receiver

The zigbee transmitter sends the patient data to the zigbee receiver. The range of zigbee is upto 100 meters only.

The receiver receives the data and process the data using ' $\mathrm{C}$ ' language and recognizes the epilepsy occurrence and take the according steps to intimate the condition of the patient to the caretaker.

\subsection{Heart beat sensor}

The Heart beat sensor recognizes the capacity of heart in terms of number of beats using sensors. The epilepsy is recognized sometimes with the abnormalities in heart beat of the patient. The trigger in this initiates the REPM algorithm i.e, to check the remaining physiological parameters of the patient to identify the epilepsy occurrence in the patient. Epilepsy is a neurological disorder which makes the up and downs in the patient heart beats.

\subsection{Temperature SENSORLM35}

The temperature sensor captures the patient body temperature for each $1000 \mathrm{~ms}$ and finds out the abnormality of the patient who is suffering from seizures. If the data is above $100^{\circ} \mathrm{C}$ then the algorithm works in finding the possibility of abnormality in heart beat, blood pressure and MEMS. LM35 series are high precision integrated circuit temperature sensors.

\subsection{Blood pressure}

In general, the epileptic patient heart beat, blood pressure normal ranges will set to a little high. The patient emotional condition makes the increase in blood pressure a lot which effects the heart rate also. According to Neuro Science, whenever there is an abnormality in these parameters can cause a seizure to a patient. So, in REPM the algorithm is designed which considers the pre seizure blood pressure reading to make the patient alert.

\subsection{MEMS}

MEMS sensor that contains accelerometer and gyroscope. The Accelerometer data is available and it is obtained through Arduino Uno and can be viewed by serial port. Using MEMS the patient fall down can be easily recognized and after identification of abnormality in temperature, blood pressure and heart beat of the patient the REPM sends the message using Zigbee module.

\subsection{Sorce \& destination (microcontroller atmega16a)}

Atmega16 micro controller is a standard microcontroller of

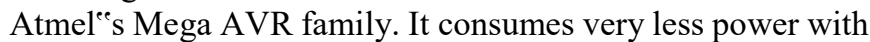
high performance. Atmega16 is based on enhanced RISC. The patient details at source node can be send to destination node using transceiver and Receiver. All the times it needs to work by sending and receiving data. So, Atmega16 is suitable for REPM to reach its objective.

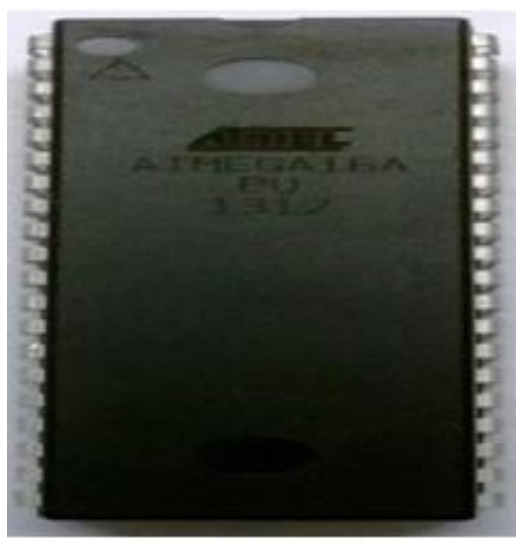

Figure 3. At mega 16 microcontrollers

\subsection{ZIGBEE module}

Zigbee module helps to send and receive the data in REPM. The patient may not all the times in town. If the patient is in driving he may got seizure and needs to get help. Using GPS the longitude and latitude can be found and patient status can be reported to the corresponding person.

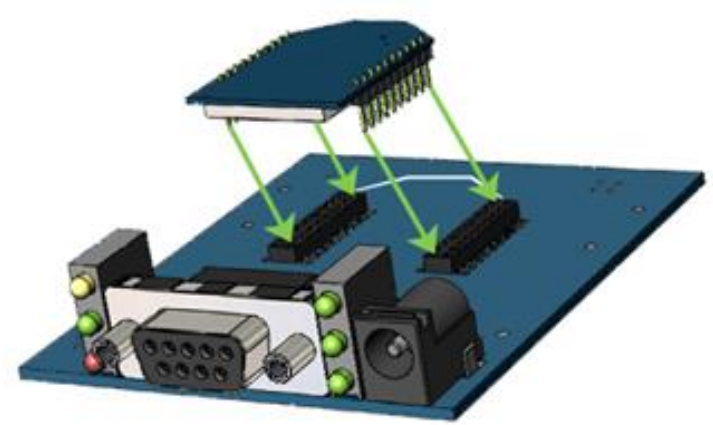

Figure 5. Zigbee module mounting to an RS232 interface board

The above figure pictorially represents the way of Zigbee module mountig to an RS232 interface board. Using Zigbee the patient abnormality can be detected.

\subsection{Arduino}

The Arduino UNO is ATmega328 based microcontroller board. It is one of the most popular prototyping boards. The board comes with built-in arduino boot loader. It has 14 GPIO pins, 6 PWM pins, 6 Analog inputs and on board UART, SPI and TWI interfaces, an on-board resonator, a reset button, and holes for mounting pin headers. While programming the board, it can be connected to the PC using USB port and the board can runs on USB power. The Arduino UNO has $32 \mathrm{~Kb}$ Flash memory, $1 \mathrm{~Kb}$ EEPROM and $2 \mathrm{~Kb}$ SRAM.

\section{EXPERIMENTAL SET UP}

The Remote Epileptic Patient Monitoring (REPM) is designed as mentioned above using Arduino and 
Zigbee with Heart beat sensor, Temparature sensor, Blood Pressure and MEMS to monitor the physiological conditions of the patient. The according experimental set up is as follows.

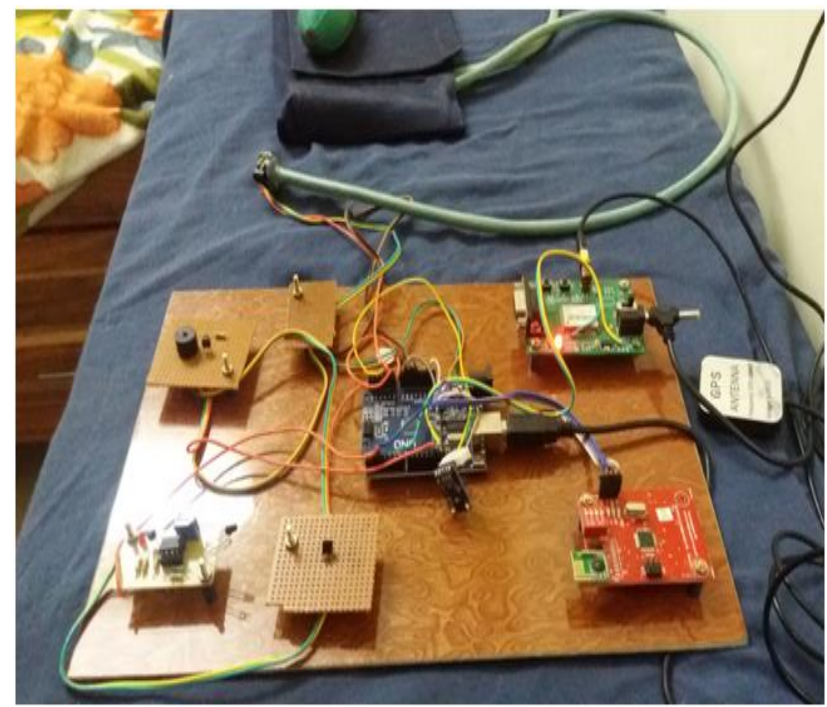

Figure 6. Experimental set up for REMP using Arduino and Zigbee

\section{RESULTS AND DISCUSSIONS}

The sensors connected to the person through Arduino to the patient collects the physiological data such as body temperature, blood pressure, heart rate and convulsions of the patient. The REPM detects the location of the patient using GPS. The patient physiological data observed abnormal then immediately it collects the location of the patient finding longitude and latitude. The REPM system is designed in such a way that

- The combination of the parameters mentioned above will accurately detects the seizure occurrence as it was not in any existing method.

- The patient can be observed remotely without any delay.

- Enhances human services administrations in risk. Saves lives and enhances nature of living utilizing remote innovation .

Arduino pins output is constantly Digital, anyway there are two distinct types of Digital Output; standard Digital Output and Pulse Width Modulation Output (PWM). Output is just with Digital pins \# 0 - \# 13. To send a Digital Output flag utilize the command:

\section{digitalWrite(pinNumber, value);}

where pinNumber represents the number of Digital pin number that is generating the signal and value possess the signal information. When generating a Digital signal the value can be either HIGH or LOW.

analogWrite(pinNumber, value);

where pinNumber represents the Digital Pin number with PWM capabilities and value is a number between 0 -255.

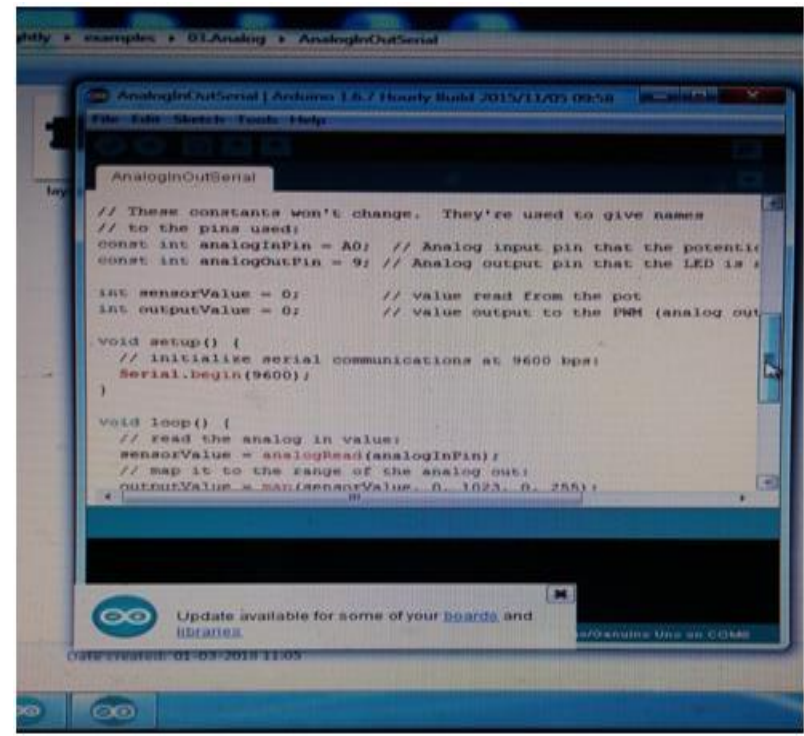

Figure 7. Setup analog out serial for sensors

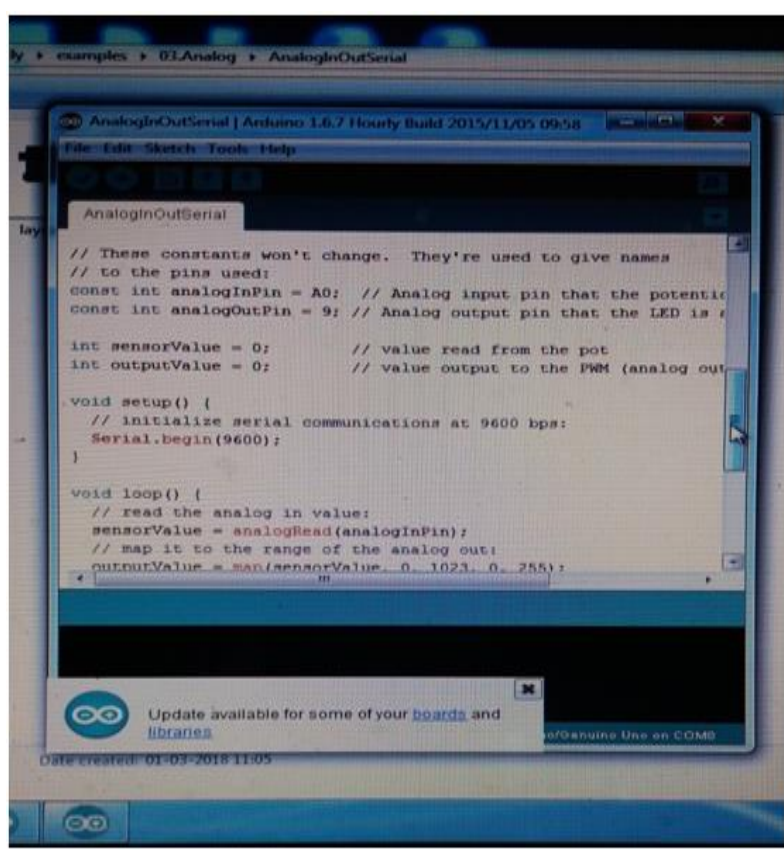

Figure 8. Analog out serial code

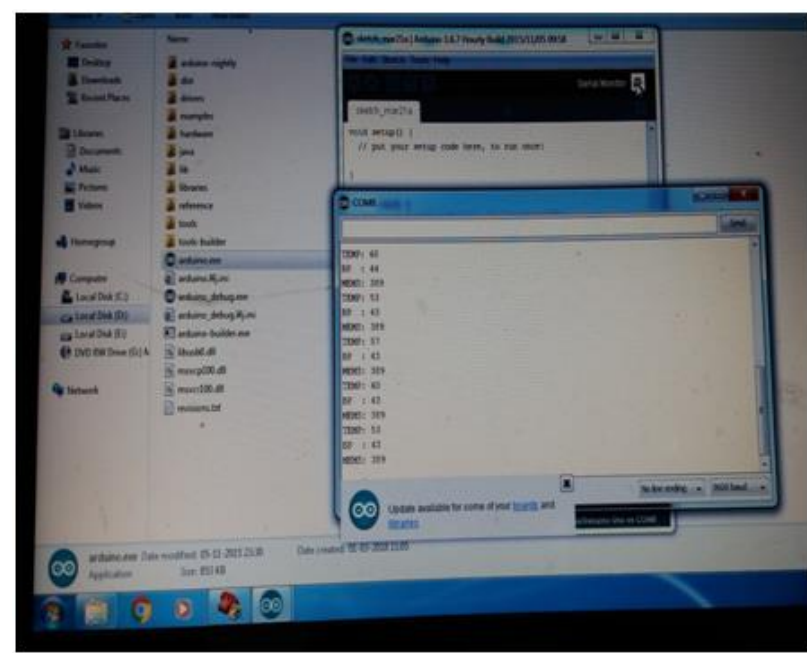

Figure 9. Pateint' Physiological conditions capturing through sensors and dispaying on remote PC' Monitor 


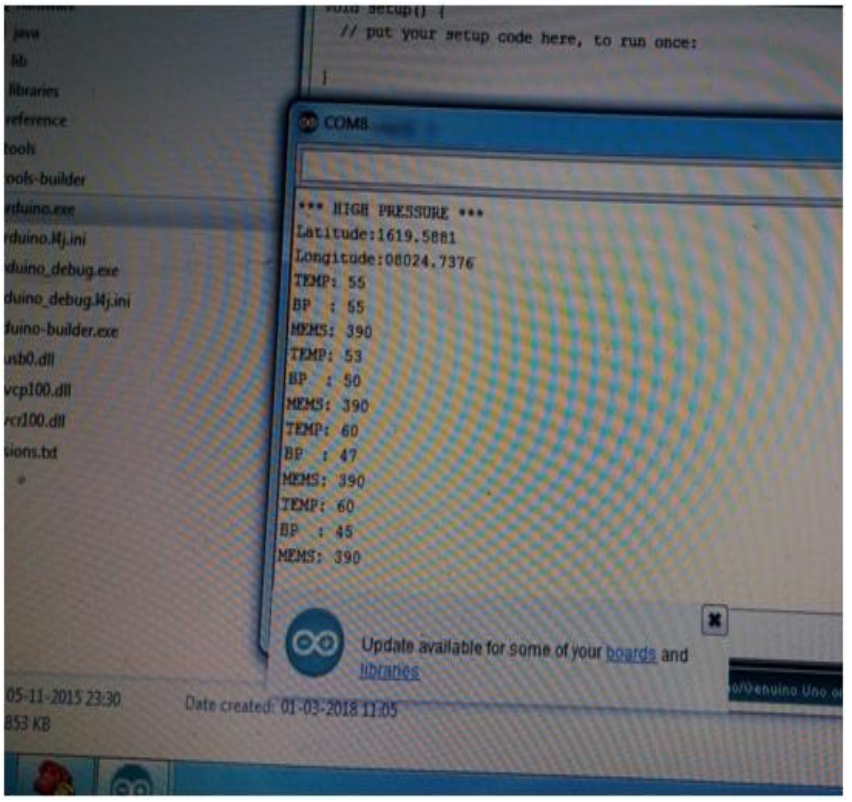

Figure 10. Pateints High Blood pressure is observed and finding the location of the patient through GPS

In this proposed work, I have utilized four differing sensors to watch the patient's health. According to the patients necessity specialist will set the periodicity of the examination in the machine. As per that the patient can experience the registration and the consequence of his health condition will be sent to the specialist instantly through an instant message utilizing GSM.

\section{CONCLUSION}

The repm system provides support and continuous monitoring of an epileptic seizure patient. the sensors identifies the physiological conditions of the patient. The muscular movements are categorized into activity and rest state of the body and the seizures are detected by observing vibrations occurring in the extremities or sudden fall because of the effect of seizure. the results are promising and are better than existing method for identification epilepsy seizure. to stay away from sudden medical issues and get more tactice in determination of the physiological states, proficient and exhaustive information gathering, observing and control assume a vital part to enhance the health care system more dependable and powerful.

\section{REFERENCES}

[1] Chipara O, Lu C, Bailey TC, Roman GC. (2009). Breliable patient monitoring: A clinical study in a stepdown hospital unit, [Dept. Comput. Sci. Eng., Washington Univ. St. Louis, St. Louis, Mo, Tech. Rep.Wucse-2009- 82, Dec. 2009.

[2] Ko J, Lim J, Chen Y, Musaloiu RE, Terzis A, Masson G, Gao T, Destler W, Selavo L, Dutton R. (2010). Bmedisn: Medical emergency detection in sensor networks. Acm
Trans. Embedded Comput. Syst. 10(1): 11:1-11:29, Article 11

[3] Lorincz K, Chen B, Challen GW, Chowdhury AR, Patel S, Bonato P, Welsh M. (2009). Bmercury: A wearable sensor network platform for high-fidelity motion analysis In Proc. 7th Acm Conf. Embedded Netw. Sensor Syst., pp. 353-366.

[4] Yager P, Edwards T, Fu E, Helton K, Nelson K, Tam MR, Weigl BH. (2006). Bmicrofluidic Diagnostic technologies for global public health. Nature 442(7101): 412-418.

[5] Mohseni P, Najafi K. (2005). A 1.48-Mw low-phasenoise analog frequency modulator for wireless biotelemetry. IEEE Trans. Biomed. Eng. 52: 938-943.

[6] Coosemans J, Puers R. (2005). An autonomous bladder pressure monitoring system. Sens. Actuat. A, 123-124, $155-161$.

[7] Troyk P, Schwan M. (1992). Closed-loop class e transcutaneous power and data link for microimplants. IEEE Trans. Biomed. Eng. 39: 589-599.

[8] Mohseni P, Najafi K, Eliades S, Wang X. (2005). Wireless multichannel biopotential recording using an integrated fm telemetry circuit. IEEE Trans. Neural Syst. Rehabil. Eng. 13: 263-271.

[9] Quwaider M, Biswas S. (2008). Body posture identification using hidden markov model with a wearable sensor network. In Proceedings of the Icst 3rd International Conference on Body Area Networks, Tempe, Az, Usa, pp. 1-8.

[10] Mark AH, Harry CP, Jr Adam TB, Kyle R, Benton HC, James HA, John L. (2009). Body area sensor networks: Challenges and opportunities. IEEE Computer Society: Atlantic City, Nj, Usa, pp. 58-65.

[11] Lo B, Yang GZ. (2005). Key technical challenges and current implementations of body sensor networks 2005 . http://ubimon.doc.ic.ac.uk/bsn/public/bsn-2005benlo.pdf

[12] Seyyed M, et al. (2011). Fuzzy logic expert systems in hos-pital: a foundation view. Journal of Applied Sciences 11(12): 2106-2110

[13] Goh KW, Lavanya J, Kim Y, Tan EK, Soh CB. (2005). A pdabased ecg beat detector for home cardiac care. In IEEE Engineering in Medicine and Biology Society, Shanghai, China, pp. 375-378.

[14] Chu HT, Huang CC, Lian ZH, Tsai TJP. (2006). A ubiquitous warning system for asthma inducement. In IEEE International Conference on Sensor Networks, Ubiquitous and Thrustworthy Computing, Taichung, Taiwan, pp. 186-191.

[15] Lin JL, Liu HC, Tai YT, Wu HS, Hsu SJ, Jaw FS, Chen YY. (2006). The development of wireless sensor network for Ecg monitoring. In 28th Annual International Conference of the IEEE, Engineering in Medicine and Biology Society, New York, Ny, Usa, pp. 3513-3516.

[16] Taylor SA, Sharif H. (2006). Wearable patient monitoring application (ecg) using wireless sensor networks. In 28th Annual International Conference on the IEEE Engineering in Medicine and Biology Society, New York, Ny, Usa, pp. 5977-5980. 